\title{
Organizational Success as a Mediating Variable of the Relationship between Organizational Learning and Organizational Excellence: A Study on Telecommunications Sector in Egypt
}

\author{
Wageeh A. Nafei ${ }^{1}$ \\ ${ }^{1}$ University of Sadat City, Menoufia, Egypt \\ Correspondence: Wageeh A. Nafei, University of Sadat City, Menoufia, Egypt. E-mail: dr.wageeh@yahoo.com
}

Received: November 29, 2017

Accepted: December 15, 2017 Online Published: December 20, 2017

doi:10.5539/ijbm.v13n1p244

URL: https://doi.org/10.5539/ijbm.v13n1p244

\begin{abstract}
The overall objective of the research is to identify the role of Organizational Success (OS) as a mediator variable in explaining the impact of Organizational Learning (OL) on Organizational Excellence (OE). The research community represents all employees at Telecommunications sector in Egypt. Due to time and cost constraints, the researcher adopted a sampling method to collect data for the study. The appropriate statistical methods were used to analyze the data and test the hypotheses.

The research found a number of results, the most important of which are: (1) there is a significant effect between OL (mechanisms and means of learning, vision and mission of the organization, empowerment of employees, knowledge management, application and use of technology) and OS (survival and growth). Multiple regression analysis model showed that there is an impact of OL as an independent variable on OS as a dependent variable; (2) there is a significant impact between OL and OE (excellence of leaders, excellence of subordinates, excellence of operations, cultural excellence and financial excellence). The multiple regression model showed that there is an impact of OL as a independent variable on OE as a dependent variable; (3) the existence of a significant effect between OS on OE, after the multi regression model showed that there is an impact of OS as a independent variable on $\mathrm{OE}$ as a dependent variable; (4) there is an impact of OS as a mediating variable in clarifying the impact of OL on OE. In other words, there is an indirect effect of the independent variable (OL) on the dependent variable $(\mathrm{OE})$ through the mediating variable $(\mathrm{OS})$; that is, OS plays the role of partial mediation in the relationship between OL and OE.

The study referred to a number of recommendations, the most important of which are: (1) attention to the process of OL, and to consider it as a tool to solve most organizational problems; (2) the interest in spreading the culture of $\mathrm{OL}$ and adopting a clear vision. This requires an organizational climate that cares about the learning process and this strengthens OS opportunities; (3) the need to invest learning in the promotion and development of OS opportunities; (4) the application of modern technology, exploiting it to the maximum possible capacity, and linking them to the process of learning and knowledge management; (5) continuing to promote policies that seek to empower workers and the need to follow the method of decentralization and delegation of authority, (6) the importance of selecting and attracting workers according to efficiency and eliminating surplus in the preparation of workers in a manner that leads to the achievement of effective performance, (7) aspiring to possess the characteristics of the OL as a strategic option to survive in a changing environment on an ongoing basis; (8) maintaining the professional competence of employees and increasing their levels as they are an important way to gain customer confidence and efficiency in service delivery.
\end{abstract}

Keywords: Organizational Learning Organizational Success, Organizational Excellence

\section{Introduction}

New concepts have emerged in the contemporary business environment which has received increasing attention recently, the most important of which is OL (Wahyuningsih et al., 2013). OL is one of the most important factors that help the organization achieve competitive advantage (Dronkolaei \& Azari, 2015). OL contributes significantly to improving the organization's competitive innovation capacity, since organizations must innovate as a prerequisite for high performance rates, and; therefore, the Organization must learn since OL contributes to different mechanisms and means of achieving competitive advantage. (Garcia-Morales et al., 2006). 
OL can attack the surrounding environment in two ways: (i) investing what is available, and (ii) changing to invest future opportunities through the ability to adapt to the leadership style, culture, processes and organizational structure, critical to OS (Macmillan \& Tampoe, 2000).

OL plays an important role as a strategic tool in modern management in order to obtain the competitive advantage of the organization and to achieve organizational stability and success. The objective of OL is not only to promote and develop the knowledge of the staff of the organization, but also to develop the strategic role of OL to create knowledge management and promote organizational objectives (Saadat \& Saadat, 2016).

The success factors of the organization are its activities, which are the responsibility of all staff at all levels of management (Meibodi \& Monavvarian, 2010).

The success of the organization depends on how well it invests in the mental capacity to impart and learn new knowledge (Dzinkowski, 2000).

The success of the organization is also linked to its ability to formulate a strategy that is consistent with the mission and vision of the organization (David, 2009).

Successful organizations have many advantages because they are highly performing because they outperform the results of the strategies they have adopted and outperform their structure, processes and systems. Successful organizations are characterized by a high understanding of their work, their commitment to achieve the results assigned to them, their regular work in the form of teams, low levels of conflict and responsibility, their ability to solve problems away from underlying conflicts, and their continued efforts to improve their work performance (Englbrt, 2003).

OE is the organization's ability to achieve its objectives in the light of customer focus, continuous learning, results orientation and employee development (Al-Dhaafri et al., 2017), for the purpose of excellence in business which includes both distinct human resources, and distinct products (Qawasmeh et al., 2013). This is in to developing and supporting the Organization's processes and management systems to improve performance and create value for stakeholders (Mann et al., 2012).

This is in addition to achieving balanced satisfaction for all customers; thus, increasing the long-term success (Breyfogle, 2008) and achieving competitive advantage in the sense of being better than competitors in one or more areas of strategic performance through quality improvement and access, on higher returns with minimal cost (Kandula, 2003).

In light of the above, the current study seeks to identify the role of OS as a mediating variable in explaining the impact of OL on OE at Telecommunications sector in Egypt.

\section{Organizational Learning}

\subsection{Organizational Learning Concept}

$\mathrm{OL}$ is the process of knowledge creation, acquisition, interpretation, transfer, and retention. In other words, it aims to provide employees with information that allows them to deal with and adapt to different situations and to benefit from them to the extent that contributes to improving the behavior of the employees of the organization. OL is a process of interaction between the organization and its members, which leads to the development of their capabilities and the strengthening of the competitive position of the organization and adaptation to the environment (Erhan \& AlparOLan, 2015).

$\mathrm{OL}$ is the process of intense interaction around an organization in which learning is aimed at changing or developing old knowledge. It is the process of developing the skills and capabilities of the staff of the organization, which achieves its distinction and adapts to environmental changes. This requires ensuring continuity of learning process (Döös et al., 2015).

$\mathrm{OL}$ is the process of acquiring, interpreting and disseminating information, bringing the Organization to an advanced stage of improvement and organizational growth, or the planned vision for the survival and growth of the Organization, by taking advantage of its expertise and experience and solving its problems to reach it and its members to the level that ensures its policies and future goals, resulting in the highest degree of efficiency and competition, sound decision making and improved organizational performance (Mohan, et al., 2015).

OL can be described as the process that reflects the organization's ability to access information and the process of storing and retrieving new information. In other words, it is a process of searching for information, translating it in order to achieve the objectives of the organization, and developing the center for competition (Lilien \& Gerwal, 2012). 
OL is the ability to acquire and use knowledge to share and use in the organization, in order to develop the skills of its employees. It is the organization's planned change process, through the effective use of knowledge in an organizational culture based on the shared vision of the members of the organization, and encouraging continuous learning, which helps the organization achieve its goals (Nazem \& Matlabi, 2011).

OL is the ability to study and adopt new ideas and transform them into policies and action plans to survive under competitive conditions. It is the process of improving the organization's capabilities and developing them, activating their relations with the environment, and adapting them to their internal and external variables (Van Grinsven \& Visser, 2011).

OL is a set of organizational actions, such as acquiring, distributing, and interpreting knowledge. It is a process in which efforts interact to enable staff to develop knowledge and use it to solve problems. This means that OL is the process of building, organizing, and improving knowledge in order to solve the problems faced by the organization (Sharifi \& EOLamieh, 2008).

OL is the process of creating and acquiring knowledge, with the aim of benefiting from it in developing its resources in a way that contributes to improving organizational performance. It is the process of correcting errors through the development and development of workers through the relationships that link behavior with the results achieved; namely, the ability of the organization to learn through experience and the desire to learn from all experiences (Lopez et al., 2005).

$\mathrm{OL}$ is a repetitive process of action and reaction, and it is evaluated from time to time by its administrators (Edmonson, 2002).

OL is the process of achieving benefits that contribute significantly to the achievement of the Organization's goals (Williams, 2001).

OL as a system includes vision, strategy, culture, leadership, structure, systems, and processes (Stratigos, 2001).

$\mathrm{OL}$ is the process of improving the capacity of the organization's members in a way that helps them better understand the vision and mission of the organization and the environment in which they are handled (Jones, 2000).

\subsection{Organizational Learning Dimensions}

The dimensions of OL are the dynamics of learning, conversion of the organization, employee empowerment, knowledge management, and the application of technology (American Society for Training and Development, 2002). They are as follows:

1. The Dynamics of Learning: The ability of the senior management of the organization to encourage the workers in the process of learning, listen to their ideas, pay attention to their training, their ability to learn from the performance of their work, and the need of the attention of the senior management of the Organization all employees.

2. Conversion of the Organization: The importance of senior management to the vision of the learning organization and providing an organizational climate that is concerned with the learning process, the interest of the management of the organization learning failure and learn from success, and the need to take into account the processes and programs in the organization as a great opportunity to learn, ease of communication.

3. Employee Empowerment: The importance of the management of the organization in the process of empowerment of employees, following the management of the organization of the method of decentralization and delegation of authority, attention by the senior management of the organization in the process of training and development of staff, attention of the senior management of the organization of the need to share their ideas and the importance of the senior management of the Organization of the process of learning from associations and universities.

4. Knowledge Management: The importance of senior management to monitor what others do outside the organization, the interest of employees to identify the best practices in their work, the attention of senior management to the skills of creative thinking of employees, and the attention of senior management to identify new ways of work, knowledge, and senior management's interest in developing strategies for the learning process.

5. Application of Technology: The attention of senior management to the need for a good information system, the attention of senior management of the need to provide information quickly, the attention of senior management to provide electronic means in the training process, the attention of senior management of the system of real-time processing and the attention of senior management of electronic systems in the learning process. 


\section{Organizational Success}

\subsection{Organizational Success Concept}

OS is the success of the project as a balancing of competition requirements related to quality, time, cost, and meeting different desires and expectations (Aga et al., 2016).

OS is the achievement of the organization's goals in terms of different aspects of performance in terms of financial perspective, customers, internal processes, learning and organizational growth. (Donsophon et al., 2016).

OS is the degree to which the organization is able to achieve its long-term sustainability objectives (Fleck, 2009).

OS is the ability of the organization to achieve its mission and objectives in order to achieve outstanding performance. The key elements of OS can be expressed in the form of an equation that is OS = message + strategic objectives + outstanding performance (Whitney, 2010)

OS is the organization's ability to coordinate its activities in the light of a shared vision of all stakeholders with the aim of achieving its objectives (Dell \& Kramer, 2003).

OS is the ability of the organization to achieve its long-term goals and to achieve a balance between its goals and those of its employees (Kenny, 2001).

OS is the ability of the organization to achieve the organization's goals through expansion, renewal, organizational survival, and continued delivery of products or services to markets (Whetten, 1987).

\subsection{Organizational Success Dimensions}

The OS dimensions of the organization are organizational survival and organizational growth (Simon et al., 2011). These can be illustrated as follows:

\section{1). Organizational Survival}

It means the organization's ability to achieve customer satisfaction and loyalty. There should be a system for receiving customer complaints and suggestions. Satisfaction should be a part of the culture of the organization and all employees involved in decision making.

2). Organizational Growth

It means the ability of the organization to fulfill its social responsibilities to ensure the training of employees, to be keen on identifying the needs and desires of the parties working with the organization, the need to conduct studies and meetings to identify the satisfaction of employees, and the need for diversity in incentive programs and; finally, the need to pay attention to the language of dialogue with the staff of the organization.

\section{Organizational Excellence}

\subsection{Organizational Excellence Concept}

$\mathrm{OE}$ is the ability of the organization to achieve its objectives by using available resources efficiently and effectively (Al Hila \& Al Shobaki, 2017).

$\mathrm{OE}$ is the unique practice of the organization to achieve a set of key concepts: customer focus, management through processes and facts, continuous learning, partnership development and social responsibility, results orientation, leadership and goal setting, individual development and participation, innovation, and improvement (Al-Dhaafri et al., 2017).

$\mathrm{OE}$ is the ongoing effort to establish an internal framework for standards and processes that aim to engage and motivate employees to deliver products and services that meet customer needs and expectations (Saleh \& Watson, 2017).

$\mathrm{OE}$ is excellence in business, which includes distinct human resources, distinct partnerships, distinct operations, and outstanding products (Qawasmeh et al., 2013).

$\mathrm{OE}$ is the development and support of organizational processes and systems to improve performance and create value for stakeholders. OE is much more than a quality system, which means achieving excellence in everything the organization does (Mann et al., 2012).

$\mathrm{OE}$ is the unique practice of managing organizations and delivering values to customers and other stakeholders (Antony \& Bhattacharyya, 2010).

$\mathrm{OE}$ is the investment of organizations by the critical opportunities ahead of effective strategic planning and the commitment to a common vision that is clear of purpose, resource adequacy, and performance (Pinar \& Girard, 2008). 
OE is the overall method of work that leads to balanced satisfaction of all stakeholders; thus, increasing the likelihood of success in the long run (Breyfogle, 2008).

Excellence not only means success but includes success, excellence and uniqueness for survival and growth. Growth and excellence are two sides of a single coin (Seymour \& Barker, 2004).

$\mathrm{OE}$ is the achievement of a sustainable competitive advantage in the sense that it is better than competitors in one or more areas of strategic performance by improving quality and achieving higher returns at the lowest cost (Kandula, 2003).

$\mathrm{OE}$ is the ability of the organization to provide opportunities, and the appropriate environment that seeks to stimulate, correct and effectively address problems (Grote, 2002).

\subsection{Organizational Excellence Dimensions}

The dimensions of $\mathrm{OE}$ are leaders' excellence, subordinates excellence, operational excellence, culture excellence, and financial excellence (Kandule, 2002; Hesseblin \& Johanston, 2002). They are as follows:

1. Leaders Excellence: The interest of senior management to discover opportunities, trying to exploit them, the pursuit of senior management to achieve a privileged position, holding the senior management some of the risks in order to achieve its objectives, administrative transparency within the organization, the attention of senior management in the spirit of positive competition between employees, the senior management accepting the initiatives that are commensurate with the nature of the work, the interest of senior management in providing a climate of creativity, and encouraging the learning process.

2. Subordinates Excellence: the availability of human resources to solve their problems, the participation of staff in the decision-making of the organization, the orientation and loyalty of employees to the organization, the ability of workers to solve the problems facing them at work, and the ability of workers to assume responsibilities for their functions, in the Organization.

3. Operational Excellence: All operations related to the provision of services are subject to continuous monitoring, the Organization's adoption of modern technology in service delivery, fast and comfortable service delivery, and the Organization's ongoing monitoring commitment to improve service delivery mechanisms and the Organization's adoption of technology in the design and delivery of services.

4. Cultural Excellence: It means the organization's ability to create a culture of learning, encouraging the organization to create new ideas, exchanging ideas among employees, using all data available to access knowledge, and the flexibility of the organization's management to accept the ideas of its employees.

5. Financial Excellence: The availability of financial resources in the Organization to cover all of its operational needs, regular monitoring of service costs by the Organization, clear measures of the various financial objectives, the Organization's commitment to rationalize its administrative expenses and control over operational costs and the Organization's good management of liquidity, and cash flows.

\section{Research Model}

The proposed comprehensive conceptual model is presented in Figure (1). The diagram below shows that there is one independent variable of OL. There is one dependent variable of OE.

There is one mediating variable of OS. It shows the rational link among the three types of observed variables. From the above discussion, the research model is as shown in the Figure (1).

The research framework suggests that OS plays a significant role in the relationship between OL and OE.

OL as measured consisted of the dynamics of learning, conversion of the organization, employee empowerment, knowledge management, and the application of technology (American Society for Training and Development, 2002).

OS is measured in terms of organizational survival and organizational growth (Simon et al., 2011).

OE is measured in terms of leaders' excellence, subordinates excellence, operational excellence, culture excellence, and financial excellence (Kandula, 2002; Hesseblin \& Gohanston, 2002). 


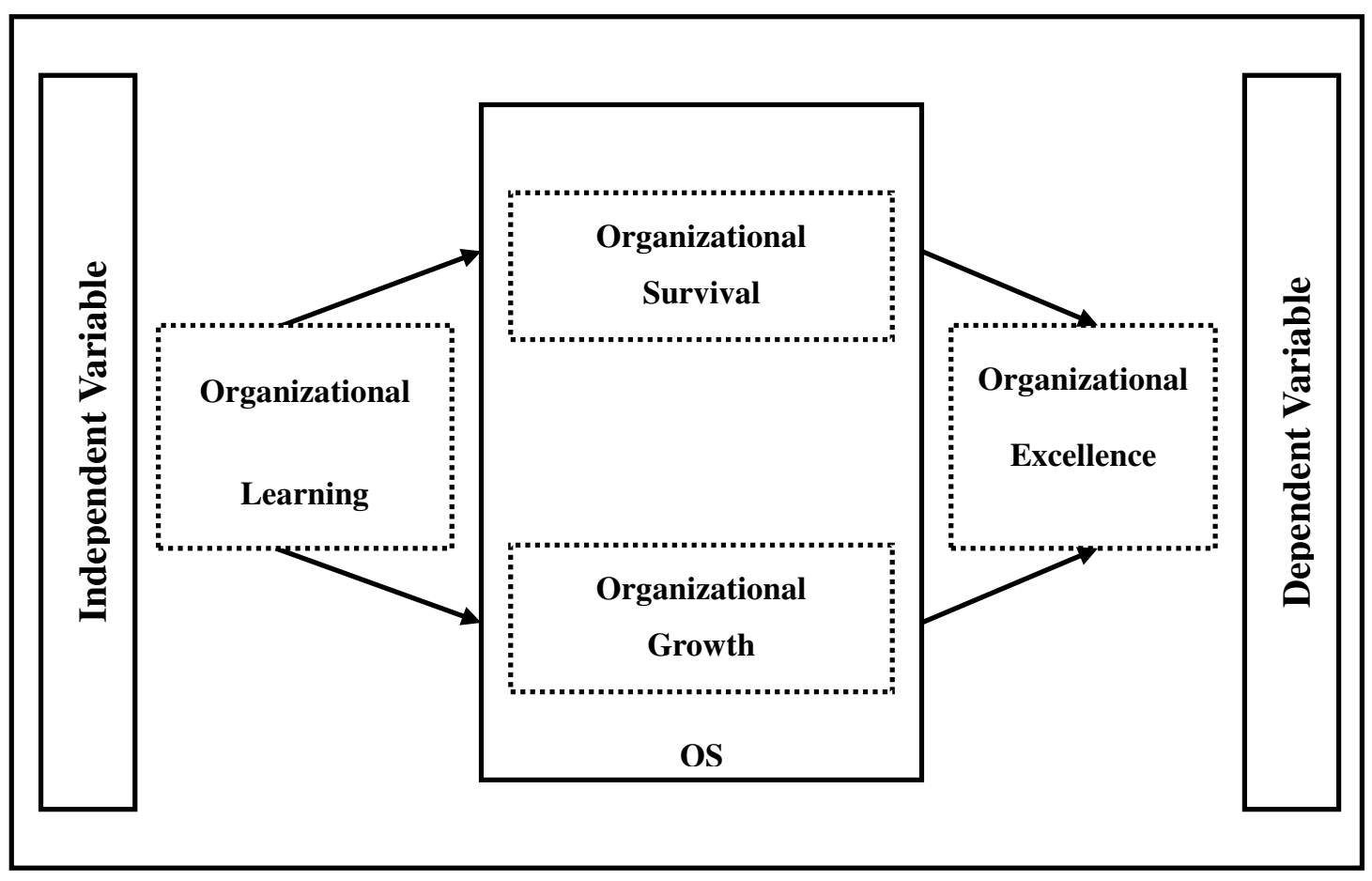

Figure 1. Proposed comprehensive conceptual model

\section{Research Questions}

The researcher reached the research problem through two sources. The first source is to be found in previous studies; it turns out that there is a lack in the number of literature reviews that dealt with the analysis of the relationship between OL, OS and OE at Telecommunication sector in Egypt. This called for the researcher to test this relationship in the Egyptian environment.

In light of the review of previous studies towards OL, literature has shown that trust in and care for workers is directly related to OL (Louis et al., 2017). The study also noted that OL plays the mediating role of the relationship between the exercise of management and competitive advantage (Oh \& Kuchinke, 2017). Another study pointed out that there is a significant relationship between $\mathrm{OL}$ and the profitability of the organization in light of the competitive advantage as an intermediate variable. The study also noted that OL is closely related to competitive advantage. Finally, the study pointed out that there is an indirect relationship between OL and the profitability of the organization, which is characterized by the competitive advantage of the organization (Maiga et al., 2015). In addition, transformational leadership positively affects organizational performance on the one hand, and OL capacity on the other. The study also indicated a positive relationship between OL and organizational performance (Mutahar et al., 2015). Another study indicated that OL played an intermediate role in the relationship between knowledge management and organizational performance. One study also showed that there is a positive relationship between knowledge management and OL on the one hand and organizational performance on the other (Luxmi, 2014). Finally, another study indicated a significant relationship between learning process and organizational commitment (Mehrabi et al., 2013).

As for the OS, the literature indicated that effective governance fosters OS (Musawir et al., 2017). In addition, another study showed that OL plays a key role in achieving OS (Saadat et al., 2016). One study found a significant relationship between the maturity of project management and OS dimensions (Berssaneti \& Carvalho, 2015). A third study indicated that there is a statistically significant relationship between strategic capacity and OS dimensions (Simon et al., 2011).

The literature review for $\mathrm{OE}$ indicated that there is a fundamental relationship between knowledge management and OE (Ahmed \& Elhag, 2017). In addition, another study showed that OE contributes significantly to the promotion and development of knowledge and creativity in the organization (Gloet \& Samson, 2017). Another study noted that leadership excellence positively affects intellectual capital (Metaxas, 2017). A third study showed that the potential and skills of workers is one of the most important themes that contribute significantly to the achievement of OE (Terouhid \& Ries, 2016). A fourth study found that building work teams effectively contributes to OE (Rao, 2016). 
The second source for the research problem is the pilot study, which was conducted in an interview with (30) employees in order to identify the relationship between OL, OS and OE. The researcher found, through the pilot study, several indicators; notably, the important and vital role that could be played by OL in reinforcing OE at Telecommunication sector in Egypt.

As a result of the discussions given above, the research questions of this study are as follows:

Q1: What is the nature and extent of the relationship between OL (dynamics of learning, conversion of the organization, employee empowerment, knowledge management, and the application of technology) and OS at Telecommunication sector in Egypt?.

Q2: What is the extent of the relationship between OL (dynamics of learning, conversion of the organization, employee empowerment, knowledge management, and the application of technology) and $\mathrm{OE}$ at Telecommunication sector in Egypt?.

Q3: What is the nature of the relationship between OS (organizational survival and organizational growth) and OE at Telecommunication sector in Egypt?

Q4: What is the role of OS as a mediating variable between OL and OE at Telecommunication sector in Egypt?

\section{Research Hypotheses}

In the light of a review of previous studies towards OL, literature has shown that there is a positive relationship between learning and organizational innovation. OL also plays the role of the intermediate variable between leadership style and organizational innovation (Liao et al., 2017). The study also indicated that a good training program plays an important role in improving OL (Hassan et al., 2016). There is also a strong relationship between leadership and OL (Golmoradi \& Ardabili, 2016). One study found that OL capacity significantly affects organizational performance. OL capacity also mediates the relationship between human resources information system and organizational performance (Lukito et al., 2016). Another study indicated that there is a strong correlation between innovation strategy and OL. OL also plays the role of the intermediate variable in the relationship between creativity strategy and creative performance (Beyene et al., 2016). In addition, both TQM and learning ability have a significant impact on organizational performance. OL capacity also plays the role of the intermediate variable between TQM and organizational performance (Mahmood et al., 2015). Another study noted that OL has an impact on organizational performance (Mohan, et al., 2015). OL directly and indirectly impacts knowledge management on organizational capacity, directly affecting organizational performance, and indirectly on organizational performance (Wahyuningsih et al., 2013). OL also has a significant impact on organizational effectiveness. And that absorptive capacity plays the role of the intermediate variable between OL and organizational effectiveness (Ologbo, 2013). Finally, another study indicated a positive relationship between individuals' ability to learn and organizational performance (Goh et al., 2012).

As for the OS, the literature indicated that there is a positive relationship between the dimensions of the strategy of administrative professionalism and OS. Both job satisfaction and organizational citizenship behavior play the role of intermediate variables in the relationship between management strategy and OS (Donsophon et al., 2016). In addition, another study showed that there is a statistically significant relationship between funding leadership and OS in light of the medium variable which is the role of the team. Team building partly contributes to the impact of leadership on OS (Aga et al., 2016).

Finally, the literature review for OE has shown that there is a statistically significant relationship between servant leadership and organizational performance (Alhila \& Alshobaki, 2017). Another study indicated that there was a positive relationship between organizational resource planning and OE. TQM partly mediates the relationship between organizational resource planning and organizational performance, and OE fully mediates the relationship between organizational resource planning and organizational performance. There is also a significant effect of OE on organizational performance (Al.Dhaafri et al., 2016). One study found that change is inevitable to achieve OE (Rao, 2015). Finally, another study pointed to the need to pay attention to technology management and investment which plays an important role in achieving OE (Ramanathan, 2004). The following hypotheses were developed to test if there is significant correlation between OL, OS and OE.

H1: OL (dynamics of learning, conversion of the organization, employee empowerment, knowledge management, and the application of technology) has no statistically significant effect on OS at Telecommunication sector in Egypt.

$\mathrm{H} 2$ : There is no statistically significant relationship between OL (dynamics of learning, conversion of the organization, employee empowerment, knowledge management, and the application of technology) and $\mathrm{OE}$ at Telecommunication sector in Egypt. 
H3: There is no statistically significant impact of OS (organizational survival and organizational growth) and OE at Telecommunication sector in Egypt.

H4: There is no statistically significant effect of OS as a mediating variable between OL and OE at Telecommunication sector in Egypt.

\section{Research Strategy}

\subsection{Population and Sample}

The population of the study included all employees at Telecommunication sector in Egypt. The total population is 1196 employees. Determination of respondent sample size was calculated using the formula (Daniel, 1999) as follows:

$$
\mathrm{n}=\frac{N \times(Z)^{2} \times P(1-P)}{d^{2}(N-1)+(Z)^{2} \times P(1-P)}
$$

A number of samples, obtained by 290 employees at Telecommunication sector in Egypt, are shown in Table (1).

Table 1. Distribution of the sample size

\begin{tabular}{llll}
\hline $\begin{array}{l}\text { Telecommunication Sector } \\
\text { in Egypt }\end{array}$ & Numbers & Percentage & Sample Size \\
\hline 1. Telecom Egypt & 812 & $68 \%$ & 290X 68\% $=197$ \\
2. Vodafone & 134 & $11 \%$ & 290X 11\% $=32$ \\
3. Mobinil & 128 & $11 \%$ & 290X 11\% $=32$ \\
4. Telecommunications & 122 & $10 \%$ & 290X 10\% $=29$ \\
Total & 1196 & $100 \%$ & 290X 100\% $=290$ \\
\hline
\end{tabular}

Source: Personnel Department at Telecommunication Sector in Egypt, 2015.

Proportionality with the number of employees in the research population is proved in Table (1). By using the lists of employees at the Staff Affairs Department, Telecommunication sector in Egypt random choice of categories was attained. Table 2 illustrates the features of sample units.

Table 2. Characteristics of Items of the Sample

\begin{tabular}{llcc}
\hline Variables & & Frequency & Percentage \\
\hline \multirow{3}{*}{ 1. Sex } & Male & 175 & $73 \%$ \\
& Female & 65 & $27 \%$ \\
& Total & 240 & $100 \%$ \\
2. Marital Status & Single & 105 & $44 \%$ \\
& Married & 135 & $56 \%$ \\
& Total & 240 & $100 \%$ \\
& Under 30 & 30 & $12 \%$ \\
3. Age & From 30 to 45 & 100 & $42 \%$ \\
& Above 45 & 110 & $46 \%$ \\
& Total & 240 & $100 \%$ \\
4. Educational Level & University & 180 & $75 \%$ \\
& Post Graduate & 60 & $25 \%$ \\
& Total & 240 & $100 \%$ \\
& Less than 5 years & 50 & $21 \%$ \\
4. Period of Experience & From 5 to 10 & 100 & $42 \%$ \\
& More than 10 & 90 & $37 \%$ \\
& Total & 240 & $100 \%$ \\
\hline
\end{tabular}

\subsection{Procedure}

The goal of this study was to identify the significant role of OS in the relationship between OL and OE. A survey research method was used to collect data in this study.

The questionnaire included four questions, relating to OL, OS, OE and biographical information of employees at Telecommunication sector in Egypt.

About 290 survey questionnaires were distributed by employing diverse modes of communication, such as in person and post. Multiple follow-ups yielded 240 statistically usable questionnaires. Survey responses were $82 \%$. 


\subsection{Research Variables and Methods of Measuring}

The 26 item scale OL section is based on American Society for Training and Development (2002). There were five items measuring the dynamics of learning, five items measuring conversion of the organization, five items measuring employee empowerment, six items measuring knowledge management, and five items measuring the application of technology.

The 10- item scale of OS section is based on Simon et al., 2011. There were four items measuring organizational survival and six items measuring organizational growth.

The 28-item scale OE section is based on Kandula, 2002; Hesseblin \& Gohanston, 2002. There were six items measuring leaders' excellence, seven items measuring subordinates excellence, five items measuring operational excellence, five items measuring culture excellence, and five items measuring financial excellence.

Responses to all items scales were anchored on a five (5) point Likert scale for each statement ranging from (5) "full agreement," (4) for "agree," (3) for "neutral," (2) for "disagree," and (1) for "full disagreement."

\subsection{Methods of Data Analysis and Testing Hypotheses}

The researcher has employed the following methods: (1) Cronbach's Alpha, (2) Multiple Regression Analysis (MRA), and (3) the statistical testing of hypotheses which includes F- test and T-test. They are found in SPSS. Also, the researcher used the Analysis of Moment Structure (AMOS) to measure the direct and indirect effects of OL on $\mathrm{OE}$, as well as the measurement of the intermediate role of OS, through the indicators of conformity of alternative models on the one hand and the model that achieves these indicators on the other.

\section{Hypotheses Testing}

Before testing the hypotheses and research questions, descriptive statistics were performed to find out means and standard deviations of OL, OS and OE.

Table (3) shows the mean and standard deviations OL, OS and OE

\begin{tabular}{cccc}
\hline Variables & The Dimension & Mean & $\begin{array}{c}\text { Standard } \\
\text { Deviation }\end{array}$ \\
\hline \multirow{3}{*}{ OL } & The Dynamics of Learning & 3.32 & 0.971 \\
& Conversion of the Organization & 3.50 & 0.946 \\
& Employee Empowerment & 3.51 & 0.938 \\
& Knowledge Management & 3.39 & 0.912 \\
& The Application of Technology & 3.59 & 0.926 \\
& Total Measurement & 3.46 & 0.916 \\
\multirow{2}{*}{ OS } & Organizational Survival & 3.66 & 1.32 \\
& Organizational Growth & 3.56 & 1.26 \\
& Total Measurement & 3.97 & 1.41 \\
& Leaders Excellence & 3.56 & 1.26 \\
& Subordinates Excellence & 3.57 & 1.25 \\
OE & Operational Excellence & 3.70 & 1.21 \\
& Culture Excellence & 3.61 & 1.33 \\
& Financial Excellence & 3.59 & 1.24 \\
& Total Measurement & 3.60 & 1.24 \\
\hline
\end{tabular}

According to Table 4, the first issue examined was the different facets of OL (the dynamics of learning, conversion of the organization, employee empowerment, knowledge management, and the application of technology). Most of the respondents identified the presence of the dynamics of learning $(M=3.32, S D=0.971)$, conversion of the organization $(M=3.50, S D=0.946)$, employee empowerment $(M=3.51, S D=0.938)$, knowledge management $(M=3.39, S D=0.912)$, and the application of technology $(M=3.59, S D=0.926)$.

The second issue examined was the different facets of OS (organizational survival and organizational growth). Most of the respondents identified the presence of organizational survival $(M=3.66, S D=1.32)$ and organizational growth $(M=3.56, S D=1.26)$.

The third issue examined was the different facets of OE (leaders' excellence, subordinates excellence, operational excellence, culture excellence, and financial excellence). Most of the respondents identified leaders excellence $(M=3.56, S D=1.26)$, subordinates excellence $(M=3.57, S D=1.25)$, operational excellence $(M=3.70, S D=1.21)$, culture excellence $(M=3.61, S D=1.33)$, and financial excellence $(M=3.59, S D=1.24)$. 


\subsection{Evaluating Reliability}

Data analysis was conducted. All scales were first subjected to reliability analysis. Cronbach's Alpha was used to assess the reliability of the scales. Item analysis indicated that dropping any item from the scales would not significantly raise the alphas.

To assess the reliability of the data, Cronbach's Alpha test was conducted. Table (4) shows the reliability results for $\mathrm{OL}, \mathrm{OS}$ and $\mathrm{OE}$.

All items had alphas above 0.70 and were therefore excellent, according to Langdridge's (2004) criteria.

Table 4. Reliability of OL, OS and OE

\begin{tabular}{|c|c|c|c|}
\hline Variables & The Dimension & $\begin{array}{l}\text { Number of } \\
\text { Statement }\end{array}$ & ACC \\
\hline \multirow{6}{*}{$\mathrm{OL}$} & The Dynamics of Learning & 5 & 0.796 \\
\hline & Conversion of the Organization & 5 & 0.770 \\
\hline & Employee Empowerment & 5 & 0.749 \\
\hline & Knowledge Management & 6 & 0.776 \\
\hline & The Application of Technology & 5 & 0.751 \\
\hline & Total Measurement & 26 & 0.957 \\
\hline \multirow{3}{*}{ OS } & Organizational Survival & 4 & 0.941 \\
\hline & Organizational Growth & 6 & 0.958 \\
\hline & Total Measurement & 10 & 0.975 \\
\hline \multirow{6}{*}{$\mathrm{OE}$} & Leaders Excellence & 6 & 0.958 \\
\hline & Subordinates Excellence & 7 & 0.963 \\
\hline & Operational Excellence & 5 & 0.959 \\
\hline & Culture Excellence & 5 & 0.954 \\
\hline & Financial Excellence & 5 & 0.944 \\
\hline & Total Measurement & 28 & 0.991 \\
\hline
\end{tabular}

Table 4 presents the reliability of OL. The reliabilities of the dynamics of learning, conversion of the organization, employee empowerment, knowledge management, and the application of technology are generally higher. The 26 items of OL are reliable because the Cronbach's Alpha is 0.957.

The dynamics of learning, which consists of 5 items, is reliable because the Cronbach's Alpha is 0.796.

The 5 items related to conversion of the organization, are reliable because the Cronbach's Alpha is 0.770 while the 5 items of employee empowerment are reliable because the Cronbach's Alpha is 0.749 .

Knowledge management, which consists of 6 items, is reliable because the Cronbach's Alpha is 0.776 . The 5 items related to the application of technology are reliable because the Cronbach's Alpha is 0.751.

According to Table 4, the 10 items of OS are reliable because the Cronbach's Alpha is 0.975 .

The organizational survival, which consists of 4 items, is reliable because the Cronbach's Alpha is 0.941 .

The 6 items related to organizational growth, are reliable because the Cronbach's Alpha is 0.958 . Thus, the internal consistency of OS can be acceptable.

Table 4 presents the reliability of $\mathrm{OE}$. The 28 items of $\mathrm{OE}$ are reliable because the Cronbach's Alpha is 0.991.

The leader excellence, which consists of 6 items, is reliable because the Cronbach's Alpha is 0.958.

Subordinates excellence which consists of 7 items, is reliable because the Cronbach's Alpha is 0.963 .

The 5 items related to operational excellence, are reliable because the Cronbach's Alpha is 0.959 while the 5 items of cultural excellence are reliable because the Cronbach's Alpha is 0.954 .

The financial excellence, which consists of 5 items, is reliable because the Cronbach's Alpha is 0.944. Thus, the reliability of $\mathrm{OE}$ can be acceptable.

Accordingly, three scales were defined, OL (26 variables), where Cronbach's Alpha represented about 0.957, OS (10 variables), where Cronbach's Alpha represented about 0.975, and OE (28 variables), where Cronbach's Alpha represented 0.991. 


\subsection{The Correlation among the Research Variables}

Table 5. Means, Standard Deviations and intercorrelations among variables

\begin{tabular}{lccccc}
\hline Variables & Mean & $\begin{array}{c}\text { Std. } \\
\text { Deviation }\end{array}$ & OL & OS & OE \\
\hline $\begin{array}{l}\text { Organizational } \\
\text { Learning }\end{array}$ & 3.46 & 0.916 & 1 & & \\
$\begin{array}{l}\text { Organizational } \\
\text { Success }\end{array}$ & 3.97 & 1.41 & $0.869^{* *}$ & 1 & \\
$\begin{array}{l}\text { Organizational } \\
\text { Excellence }\end{array}$ & 3.60 & 1.24 & $0.859^{* *}$ & $0.994^{* *}$ & 1 \\
\hline
\end{tabular}

Table 5 shows correlation coefficients between the research variables, and results indicate the presence of significant correlation between variables (OL, OS and OE). The level of OL is high (Mean=3.46; SD=0.916), while $\mathrm{OS}$ is high $(\mathrm{Mean}=3.97 ; \mathrm{SD}=1.41)$ which led to higher $\mathrm{OE}(\mathrm{Mean}=3.60 ; \mathrm{SD}=0.1 .24)$.

Table 5 reveals the correlation between $\mathrm{OL}$ and $\mathrm{OS}(\mathrm{R}=0.869 ; \mathrm{P}<0.01)$, which means that the high level of $\mathrm{OL}$ leads to higher OS. The table shows the correlation between OS and $\mathrm{OE}(\mathrm{R}=0.994 ; \mathrm{P}<0.01)$, and this shows that the high level of OS contributes to mitigation of feelings of OE. Finally, Table (5) refers to the correlation between $\mathrm{OL}$ and $\mathrm{OE}(\mathrm{R}=0.859 ; \mathrm{P}<0.01)$ implying that the high level of $\mathrm{OL}$ increases $\mathrm{OE}$.

\subsection{Organizational Learning and Organizational Success}

The relationship between OL and OS is determined. The first hypothesis to be tested is:

H1: OL (the dynamics of learning, conversion of the organization, employee empowerment, knowledge management, and the application of technology) has no statistically significant effect on OS at Telecommunication sector in Egypt.

Table 6. Correlation Matrix between OL and OS

\begin{tabular}{lllllll}
\hline Variables & 1 & 2 & 3 & 4 & 5 & 6 \\
\hline The Dynamics of Learning & 1 & & & & & \\
Conversion of the Organization & $0.956^{* *}$ & 1 & & & & \\
Employee Empowerment & $0.925^{* *}$ & $0.958^{* *}$ & 1 & & & \\
Knowledge Management & $0.955^{* *}$ & $0.972^{* *}$ & $0.964^{* *}$ & 1 & & \\
The Application of Technology & $0.944^{* *}$ & $0.913^{* *}$ & $0.925^{* *}$ & $0.910^{* *}$ & 1 & \\
Organizational Success & $0.829^{* *}$ & $0.853^{* *}$ & $0.875^{* *}$ & $0.834^{* *}$ & $0.857^{* *}$ & 1 \\
\hline
\end{tabular}

Note: ** Correlation is significant at 0.01 level.

Based on the Table 6, correlation between OL (the dynamics of learning) and OS is 0.829. For OL (conversion of the organization) and OS, the value is 0.853 whereas OL (employee empowerment) and OS show correlation value of 0.875. Also, the correlation between OL (knowledge management) and OS is 0.834, whereas OL (the application of technology) and OS show correlation value of 0.857 .

Table 7. MRA Results for OL and OS

\begin{tabular}{|c|c|c|c|}
\hline $\begin{array}{l}\text { The Variables of } \\
\text { OL }\end{array}$ & Beta & $\mathrm{R}$ & $\mathrm{R}^{2}$ \\
\hline 1. The Dynamics of Learning & 0.089 & 0.829 & 0.687 \\
\hline 2. Conversion of the Organization & $0.374^{*}$ & 0.853 & 0.727 \\
\hline 3. Employee Empowerment & $0.645^{* *}$ & 0.875 & 0.765 \\
\hline 4. Knowledge Management & $0.400^{*}$ & 0.834 & 0.695 \\
\hline 5. The Application of Technology & $0.367^{* *}$ & 0.857 & 0.734 \\
\hline - $\quad \mathrm{MCC}$ & 0.889 & & \\
\hline - $\quad \mathrm{DC}$ & 0.791 & & \\
\hline - $\quad$ Calculated F & 176.772 & & \\
\hline - $\quad$ Degree of Freedom & 5,234 & & \\
\hline - $\quad$ Indexed F & 3.01 & & \\
\hline - $\quad$ Level of Significance & 0.000 & & \\
\hline$* * \mathrm{P}<.01 * \mathrm{P}<.05$ & & & \\
\hline
\end{tabular}


As Table 7 proves, the MRA resulted in the $\mathrm{R}$ of 0.889 demonstrating that the independent variables of OL construe OS significantly. Furthermore, the value of R square, independent variables of OL can explain $58 \%$ of the total factors in OS level. Hence, $42 \%$ are explained by the other factors. Therefore, there is enough empirical evidence to reject the null hypothesis.

\subsection{Organizational Learning and Organizational Excellence}

The relationship between $\mathrm{OL}$ and $\mathrm{OE}$ is determined. The second hypothesis to be tested is:

H2: There is no statistically significant relationship between OL (dynamics of learning, conversion of the organization, employee empowerment, knowledge management, and the application of technology) and OE at Telecommunication sector in Egypt.

Table 8. Correlation Matrix between $\mathrm{OL}$ and $\mathrm{OE}$

\begin{tabular}{lllllll}
\hline Variables & 1 & 2 & 3 & 4 & 5 & 6 \\
The Dynamics of Learning & 1 & & & & & \\
Conversion of the Organization & $0.956^{* *}$ & 1 & & & & \\
Employee Empowerment & $0.925^{* *}$ & $0.958^{* *}$ & 1 & & & \\
Knowledge Management & $0.955^{* *}$ & $0.972^{* *}$ & $0.964^{* *}$ & 1 & & \\
The Application of Technology & $0.944^{* *}$ & $0.913^{* *}$ & $0.925^{* *}$ & $0.910^{* *}$ & 1 & \\
Organizational Excellence & $0.819^{* *}$ & $0.842^{* *}$ & $0.765^{* *}$ & $0.824^{* *}$ & $0.850^{* *}$ & 1 \\
\hline
\end{tabular}

Note: ** Correlation is significant at 0.01 level.

Based on the Table 8, correlation between OL (the dynamics of learning) and OE is 0.819. For OL (conversion of the organization) and OE, the value is 0.842 whereas OL (employee empowerment) and OE show correlation value of 0.765 . Also, the correlation between OL (knowledge management) and OE is 0.824 , whereas OL (the application of technology) and OE show correlation value of 0.850 .

Table 9. MRA Results for OL and OE

\begin{tabular}{|c|c|c|c|}
\hline The Variables of OL & Beta & $\mathrm{R}$ & $\mathrm{R}^{2}$ \\
\hline 1. The Dynamics of Learning & 0.123 & 0.819 & 0.670 \\
\hline Conversion of the Organization & $0.364^{*}$ & 0.842 & 0.708 \\
\hline Employee Empowerment & $0.627^{* *}$ & 0.865 & 0.748 \\
\hline 4. Knowledge Management & $0.382^{*}$ & 0.824 & 0.678 \\
\hline 5. The Application of Technology & $0.401^{* *}$ & 0.850 & 0.722 \\
\hline - $\quad \mathrm{MCC}$ & 0.880 & & \\
\hline - $\quad \mathrm{DC}$ & 0.775 & & \\
\hline - $\quad$ Calculated F & 161.090 & & \\
\hline - Degree of Freedom & 5,234 & & \\
\hline - $\quad$ Indexed F & 3.01 & & \\
\hline - $\quad$ Level of Significance & 0.000 & & \\
\hline
\end{tabular}

As Table 9 proves, the MRA resulted in the $\mathrm{R}$ of 0.880 demonstrating that the independent variables of OL construe OE significantly. Furthermore, the value of R square, independent variables of OL can explain $77 \%$ of the total factors in OE level. Hence, $23 \%$ are explained by the other factors. Therefore, there is enough empirical evidence to reject the null hypothesis.

\subsection{Organizational Success and Organizational Excellence}

The relationship between OS and OE is determined. The third hypothesis to be tested is:

H3: There is no statistically significant impact of OS (organizational survival and organizational growth) and OE at Telecommunication sector in Egypt.

Table 10. Correlation Matrix between OS and OE

\begin{tabular}{lllll}
\hline Variables & 1 & 2 & 3 \\
\hline Organizational Survival & 1 & & \\
Organizational Growth & $0.962^{* *}$ & 1 & \\
Organizational Excellence & $0.974^{* *}$ & $0.996^{* *}$ & 1 \\
\hline
\end{tabular}

Note: ** Correlation is significant at 0.01 level. 
Based on the Table 10, correlation between OS (survival) and OE is 0.974 , whereas OS (growth) and OE show correlation value of 0.996 .

Table 11. MRA Results for OS and OE

\begin{tabular}{llll}
\hline The Variables of OS & Beta & $\mathrm{R}$ & $\mathrm{R}^{2}$ \\
\hline 1. $\quad$ Organizational & $0.217^{* *}$ & 0.974 & 0.948 \\
Survival & & & \\
2. Organizational & $0.787^{* *}$ & 0.996 & 0.992 \\
Growth & 0.997 & & \\
- $\quad$ MCC $\quad$ DC & 0.993 & \\
- Calculated F & 22956.270 & \\
- Degree of Freedom & 2,237 & \\
- Indexed F & 4.60 & \\
- Level of Significance & 0.000 & \\
$* * \mathrm{P}<.01 * \mathrm{P}<.05$ & & \\
\hline
\end{tabular}

As Table 11 proves, the MRA resulted in the $\mathrm{R}$ of 0.997 demonstrating that the independent variables of OS construe OE significantly. Furthermore, the value of R square and independent variables of OS can explain $99 \%$ of the total factors in OE level. Hence, $1 \%$ is explained by the other factors. Therefore, there is enough empirical evidence to reject the null hypothesis.

\subsection{OS as a Mediating Variable of the Relationship between $O L$ and $O E$}

The statistical significant effect of OS as a mediating variable of the relationship between OL and OE is determined. The fourth hypothesis to be tested is:

H4: There is no statistically significant effect of $O S$ as a mediating variable between $O L$ and $O E$ at Telecommunication sector in Egypt.

The study of the effect of the independent variable on the dependent variable through the intermediate variable is an important subject in social studies. The researcher relied on Holmbeck (1997) to measure the role of OS as an intermediate variable in interpreting the impact of $\mathrm{OL}$ on $\mathrm{OE}$ by testing three different models. This can be illustrated as follows:

\subsubsection{Full Direct Effects Model}

This model is based on the fact that OL directly affects OE. This is in addition to the direct relationship between the mediating variable (OS) and the dependent variable (OE). The structural model of the direct and complete effect of the search variables can be illustrated in the following diagram:

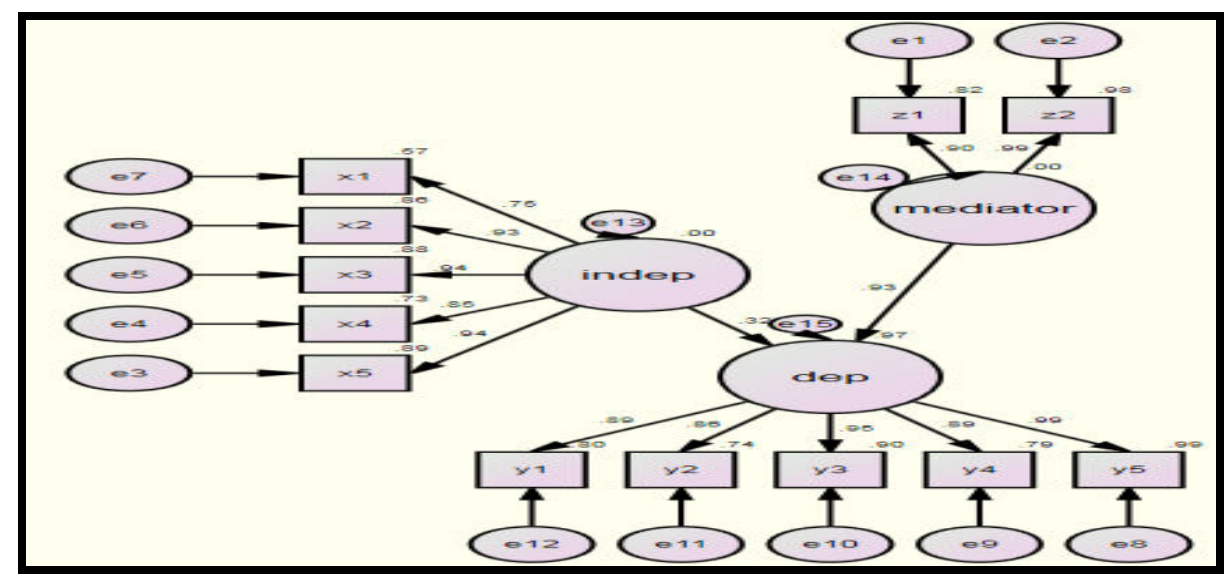

Figure 2. The structural model of the direct and complete effect of the search variables

Source: The researcher based on the outputs of AMOS, V.23, 2015. 
From the previous figure, there is a direct effect of the independent variable $(\mathrm{OL})$ on the dependent variable $(\mathrm{OE})$, and the direct effect of the variable (OS) on the dependent variable (OE). The correlation quality indicators of the direct and complete impact model can be illustrated in the following table:

Table 12. Match quality indicators for the direct impact model of search variables

${ }^{(*)}$ Daire et al., 2008

\begin{tabular}{lll}
\hline Test the Quality of the Model & Test Value & Acceptance Condition ${ }^{(*)}$ \\
\hline $\mathrm{X}^{2} /$ Degree of freedom & 34.0 & $\left(\mathrm{X}^{2} / \mathrm{df}\right)<5$ \\
P. value & 0.000 & $\mathrm{P}>0.5$ \\
Goodness of fit Index (GFI) & 0.670 & $\mathrm{GFI}>0.90$ \\
Tuker-Lewis Index (TLI) & 0.509 & $\mathrm{TLI}>0.9$ \\
Comparative Fit Index (CFI) & 0.613 & $\mathrm{CFI}>0.95$ \\
Normed Fit Index (NFI) & 0.609 & $\mathrm{NFI}>0.90$ \\
Incremental Fit Index (IFI) & 0.614 & $\mathrm{IFI}>0.9$ \\
\hline
\end{tabular}

Source: The researcher based on the outputs of AMOS, V.23, 2015

In light of the above-mentioned indicators, it is clear that the model has achieved good indicators according to the results of the analysis, where the value of $\left(\mathrm{X}^{2} /\right.$ degrees of freedom) 34.0 which is greater than (5), and the value of $\mathrm{P}$ is significant. The index of the Goodness of fit Index (GFI =0,670) is less than $(0.9)$, in addition to the Tuker-Lewis Index $(\mathrm{TLI}=0.509)$ which is less than $(0.9)$, as well as the value of the Comparative Fit Index $(\mathrm{CFI}=$ 0.613 ), less than (0.9), the Normed Fit Index (NFI = 0.609), less than 0.9, and Incremental Fit Index (IFI = 0.614), which is less than 0.9 .

Accordingly, it should be noted that all the previous indicators confirm that all model estimates are significant, indicating that there is a relationship between OL and OE on the one hand, OS, and OE on the other.

According to the above-mentioned results, it was decided to reject the null hypothesis that said "there is no significant influence of OL on OS through OE." The alternative hypothesis was accepted after it was found that the independent variable (OL) had an effect on the dependent variable (OE) on the one hand, and the direct effect of OS on the OE (dependent variable) on the other hand. This decision was based on the value of $\left(\mathrm{X}^{2} /\right.$ degrees of freedom), the value of (P), and the indicators of GFI, TLI, CFI, NFI, and IFI.

\subsubsection{Full Mediated Model}

This model is based on the fact that OS mediates the relationship between OL and OE fully. The structural model of the full mediation of the search variables can be illustrated in the following form:

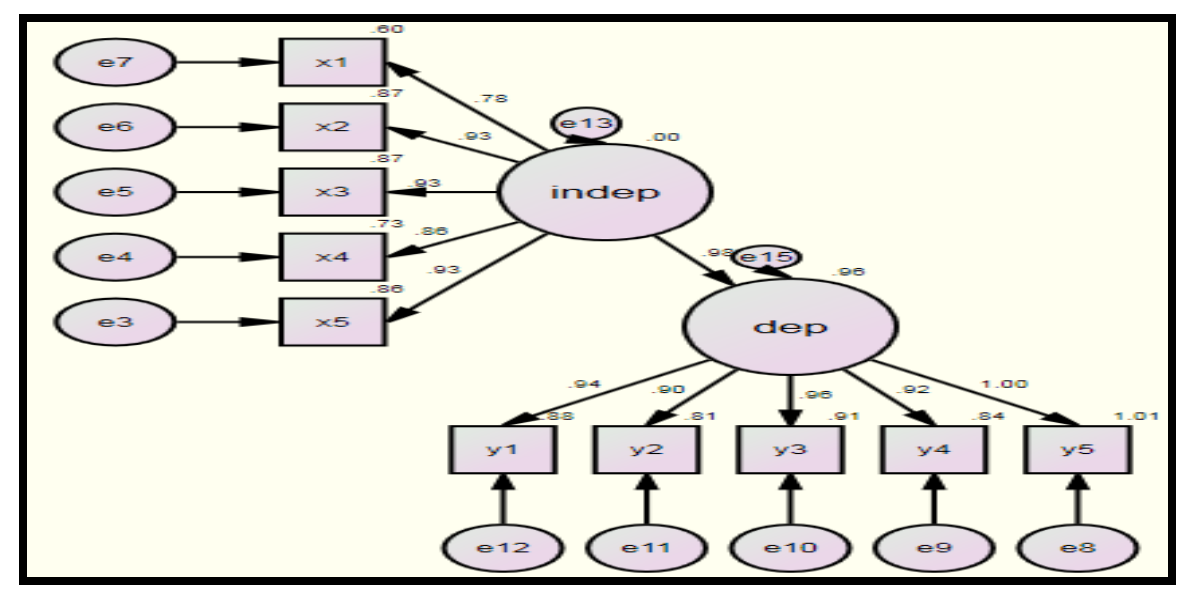

Figure 3. Structural model for full mediation of search variables

Source: The researcher based on the outputs of AMOS, V.23, 2015 
From the previous figure, it is clear that there is a direct influence of the independent variable $(\mathrm{OL})$ on the dependent variable (OE). The correlation quality indicators for this model can be illustrated by the following Table.

Table 13. Match quality indicators for the direct impact model of search variables

\begin{tabular}{|c|c|c|}
\hline Test the Quality of the Model & Test Value & Acceptance Condition $^{(*)}$ \\
\hline $\mathrm{X}^{2} /$ Degree of freedom & 32.0 & $\left(\mathrm{X}^{2} / \mathrm{df}\right)<5$ \\
\hline P. value & 0.000 & $\mathrm{P}>0.5$ \\
\hline Goodness of fit Index (GFI) & 0.715 & GFI $>0.90$ \\
\hline Tuker-Lewis Index (TLI) & 0.764 & TLI $>0.9$ \\
\hline Comparative Fit Index (CFI) & 0.822 & $\mathrm{CFI}>0.95$ \\
\hline Normed Fit Index (NFI) & 0.816 & $\mathrm{NFI}>0.90$ \\
\hline Incremental Fit Index (IFI) & 0.822 & IFI $>0.9$ \\
\hline
\end{tabular}

${ }^{(*)}$ Daire et al., 2008

Source: The researcher based on the outputs of AMOS, V.23, 2015.

According to table (13). the model achieved good indicators according to the results of the analysis, where the value ( $\mathrm{X}^{2}$ degrees of freedom) 32.0 which is greater than (5), and that the value of $\mathrm{P}$ is significant.

The index of the Goodness of fit Index (GFI $=0.715)$ is less than $(0.9)$, in addition to the Tuker-Lewis Index (TLI $=0.764)$, which is less than $(0.9)$, as well as the Comparative Fit Index $(\mathrm{CFI}=0.822)$, less than $(0.9)$, the Normed Fit Index $(\mathrm{NFI}=0.816$ ), less than 0.9, and the Incremental Fit Index (IFI $=0.822)$, which is less than 0.9.

Accordingly, it should be noted that all previous indicators confirm that all estimates of the model is significant, which shows that there is a relationship between $\mathrm{OL}$ and $\mathrm{OE}$ at Telecommunication sector in Egypt.

According to the above-mentioned results, it was decided to reject the null hypothesis that said "there is no effect of OL, on OE." The alternative hypothesis was accepted after it was found that the independent variable (OL) had an impact on the dependent variable (OE). This decision was based on the value of $\left(\mathrm{X}^{2} /\right.$ degrees of freedom), the value of $(\mathrm{P})$, and the indicators of GFI, TLI, CFI, NFI, and IFI.

\subsubsection{Partial Mediated Model}

This model is based on the indirect effect of the independent variable (OL) and the dependent variable (OE) through the intermediate variable (OS).

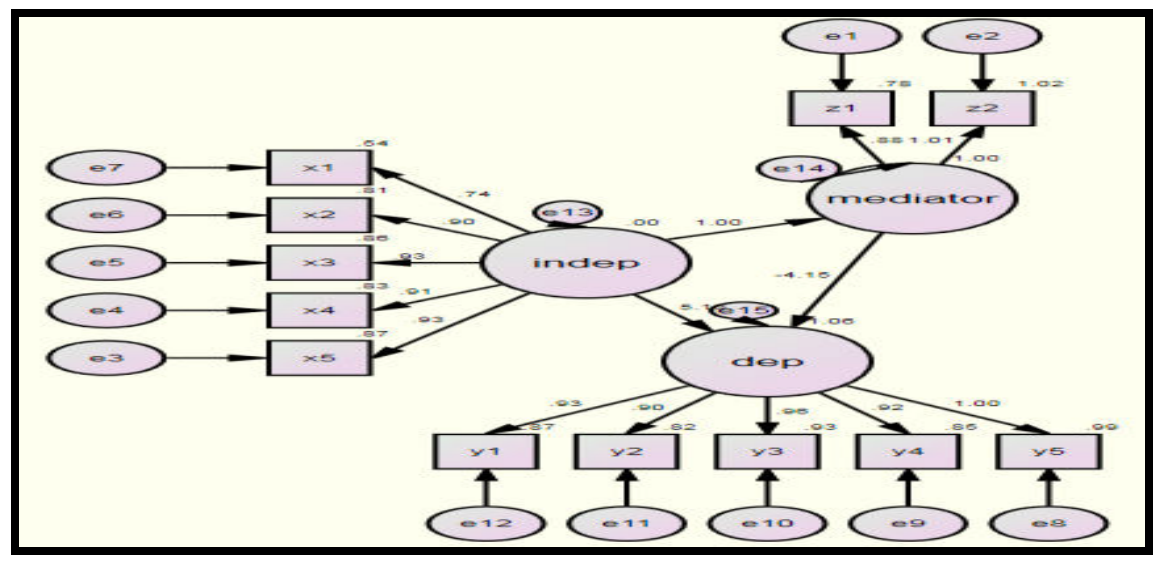

Figure 4. The structural model of the search variables

Source: The researcher based on the outputs of AMOS, V.23, 2015.

It is clear that there is an indirect influence between the OL (the independent variable) on OE (the dependent variable) and the OS (the mediating variable). The different indicators of the quality of the partial mediation model can be explained in the Table (14). 
According to Table (14), it is clear that the model achieved good indicators according to the results of the analysis, where the value of $\left(\mathrm{X}^{2} /\right.$ degrees of freedom) 31.0 which is greater than (5), and the value of $\mathrm{P}$ is significant.

The index of the Goodness of fit Index $(\mathrm{GFI}=0.753)$ is less than $(0.9)$, in addition to the Tuker-Lewis Index (TLI $=0.656)$, which is less than $(0.9)$, as well as the Comparative Fit Index $(C F I=0.734)$, less than $(0.9)$, the Normed Fit Index $(\mathrm{NFI}=0.729)$, less than 0.9, and the Incremental Fit Index $(\mathrm{IFI}=0.734)$, which is less than 0.9.

Table 14. Match quality indicators for the direct impact model of search variables

\begin{tabular}{lll}
\hline Test the Quality of the Model & Test Value & Acceptance Condition ${ }^{(*)}$ \\
\hline $\mathrm{X}^{2} /$ Degree of freedom & 31.0 & $\left(\mathrm{X}^{2} / \mathrm{df}\right)<5$ \\
P. value & 0.000 & $\mathrm{P}>0.5$ \\
Goodness of fit Index (GFI) & 0.753 & $\mathrm{GFI}>0.90$ \\
Tuker-Lewis Index (TLI) & 0.656 & $\mathrm{TLI}>0.9$ \\
Comparative Fit Index (CFI) & 0.734 & $\mathrm{CFI}>0.95$ \\
Normed Fit Index (NFI) & 0.729 & $\mathrm{NFI}>0.90$ \\
Incremental Fit Index (IFI) & 0.734 & IFI $>0.9$ \\
\hline
\end{tabular}

${ }^{(*)}$ Daire et al., 2008.

Source: The researcher based on the outputs of AMOS, V.23, 2015.

Accordingly, it should be noted that all the previous indicators confirm that all model estimates are significant, which shows that there is an indirect relationship between OL and OE through OS, that is, OS plays the role of partial mediation between OL and OE at Telecommunication sector in Egypt.

The Sobel test was carried out in order to measure the indirect effects of OL (independent variable) on OE (dependent variable) under OS (mediating variable). Therefore, the previous results are not significant unless after testing Sobel.

Table 15. Sobel Test

\begin{tabular}{ll}
\hline Significance Indirect Effect & Test Value \\
\hline Effect Degree & 0.1558 \\
Standard Error & 0.0170 \\
The Value of Calculated Z & 9.1558 \\
Degree of Freedom & 2.237 \\
The Value of Indexed Z & 1.96 \\
P. value & 0.000 \\
\hline
\end{tabular}

Source: The researcher based on the outputs of AMOS, V.23, 2015.

The Sobel test depends on the value of $Z$ value. If the $Z$ value is greater than 1.96 we conclude that the model is an intermediate variable model, that is, the indirect effect is true and vice versa if $Z$ value is less than 1.96. This can be illustrated in the following table:

From the previous table, there is a significant effect of OS (mediating variable) on the relationship between OL (independent variable) and $\mathrm{OE}$ (dependent variable).

According to the above-mentioned results, it was decided to reject the null hypothesis that said "there is no significant effect of OS a mediating variable of the relationship between OL and OE" The alternative hypothesis was accepted after it was found that that there is a significant effect of OL (independent variable) on OE (dependent variable) through the mediating variable (OS), that is, OS plays the mediating role on the relationship between OL and OE. This decision was based on the value of the $\mathrm{X}^{2} /$ degrees of freedom, the value of $\mathrm{P}$, the GFI, TLI, CFI, NFI, IFI and Sobel tests.

\section{Research Results}

By reviewing the results of descriptive analysis of the data on which the study was based and testing the hypotheses of the research, the study reached a set of results as follows: 
1. There is a significant influence between OL (the dynamics of learning, conversion of the organization, employee empowerment, knowledge management, and the application of technology) and OS (survival and growth) at Telecommunications sector in Egypt. The multiple regression model showed that there is an impact of $\mathrm{OL}$ as an independent variable on OS as a dependent variable at telecommunications sector in Egypt. This finding is consistent with Lin's 2008 study, in which he concluded that OL play an important role as a determinant of the OS. In other words, OL capabilities have a significant impact on OS. The acquisition and dissemination of knowledge are positively and successfully linked to the success of the work of the organization. Knowledge management capabilities also help to improve the competitiveness of the organization.

2. OL (the dynamics of learning, conversion of the organization, employee empowerment, knowledge management, and the application of technology), influences OE (leaders, subordinates, operational, culture, and financial). The multiple regression model showed that there is an impact of OL an independent variable on OE as a dependent variable at telecommunication sector in Egypt. This finding is consistent with Salleh's study in 2014, in which he concluded that OL can be achieved by relying on knowledge management in the transfer of implicit knowledge, plays an important role in achieving OE. In other words, there is a significant relationship between OL and the effectiveness of knowledge management in achieving $\mathrm{OE}$.

3. There is a significant influence between OS (survival and growth) on OE at Telecommunications sector in Egypt. The multi regression model showed that there is an impact of OS as an independent variable on OE as a dependent variable at telecommunication sector in Egypt.

4. There is a significant effect of the independent variable $(\mathrm{OL})$ on the dependent variable $(\mathrm{OE})$ and the significant effect of the intermediate variable (OS) on the dependent variable (OE). The effect of the variable (OS) is on the relationship of the independent variable $(\mathrm{OL})$ and the dependent variable $(\mathrm{OE})$. OS plays an intermediate role in the relationship between OL and OE at Telecommunications sector in Egypt.

5. There is an effect of the independent variable (OL) on the dependent variable (OE). In other words, OS mediates the relationship between $\mathrm{OL}$ and $\mathrm{OE}$ at Telecommunications sector in Egypt.

6. There is an impact of OL on OE through OS as an intermediate variable. In other words, there is an effect of the independent variable $(\mathrm{OL})$ on the dependent variable $(\mathrm{OE})$ through the intermediate variable $(\mathrm{OS})$. This means that OS plays the role of partial mediation in the relationship between OL and OE at Telecommunications sector in Egypt.

\section{Recommendations}

In the light of the previous results, the researcher concludes with a set of recommendations. The most important of these recommendations can be summarized as follows:

1. Attention to the process of OL and to consider it as a tool to solve most of the organizational problems. Therefore, the Egyptian telecom companies should pay close attention to the process of education permanently, as it is an important part of the daily regulatory activities and at all levels of management.

2. The interest of Egyptian telecom companies to spread the culture of OL and adopt a clear vision, and this requires an organizational climate that cares about the learning process, which leads to the promotion of OS opportunities.

3. The interest of Egyptian telecom companies in the management of knowledge in a way that achieves its interaction with learning processes, which leads to the enhancement and development of the capabilities and skills of employees in a manner that reflects the impact on the performance of the organization.

4. Invest learning in the promotion and development of OS opportunities. This can be achieved by encouraging senior management of the learning process itself, opening channels of communication, encouraging the idea of teamwork and empowering employees to perform the tasks assigned to them.

5. Apply modern technology and exploit it to the maximum potential, and linking it to the process of learning on and knowledge management leading to the ease of decision making, the efficiency of the processes that are carried out, and the quality of training programs for employees.

6. Continuing to promote policies that seek to empower workers, and the need to decentralize and delegate authority to enable these companies to achieve their objectives freely and exploit the opportunities for success they face. 
7. The importance of selecting and attracting workers according to efficiency, and disposal of surplus in the preparation of workers in a manner that leads to the achievement of effective performance.

8. Egyptian telecom companies aspire to possess the characteristics of the educated organization as a strategic option for survival and success in a constantly changing environment.

9. Interest in the process of innovation and the search for new ideas and methods. This requires the provision of the appropriate atmosphere, and the experience that was available to the employees enough to establish a tradition of work can be employed to introduce and apply new ideas.

10. To maintain the professional competence of employees and increase their levels as it is an important way to gain customer confidence and efficiency in the delivery of services.

11. Encouraging all employees to engage in dialogue and discussion, to adopt their ideas and suggestions in order to create a culture of learning from others.

12. The attention of the managers of the Egyptian telecom companies to work to cultivate a culture of excellence among the employees, and to direct their attention towards customers, on the basis that excellence can not be achieved only through the attention to customers, and deal with them well, and work to satisfy their needs and desires.

13. Paying attention to the search for methods and tools that help Egyptian telecommunications companies to achieve their objectives in order to stay and continue to provide services to their customers and the need to focus on excellence as the best option to achieve this.

14. Exploiting the human resources available in the Egyptian telecom companies as efficiently and effectively as possible, as they are the creative and intellectual energy that achieves excellence for such companies. This requires the need to develop and train employees and to follow the culture of empowering employees.

15. The interest of the managers of Egyptian telecommunications companies to work on translating the vision of these companies to a set of objectives achieved by achieving OE through the activation of administrative communication between all employees of the organization, and its customers.

16. The attention of the managers of Egyptian telecommunications companies to adopt the organizational culture that focuses on the idea of participation among all employees in the organization, through participation in the development of plans and strategies, and its objectives with the need to coordinate between all parties concerned in a manner that achieves efficiency and effectiveness in achieving OE.

17. Having a clear vision for the Egyptian telecom companies and translate them into a set of objectives and activities in light of the promotion and development of human capabilities, and to adopt a culture that focuses on empowering employees, participation of decision makers, partnership in taking responsibility, accepting change and using technology. This needs achieving coordination between the parties dealing with the Organization.

18. Drawing the attention of the managers of the Egyptian telecommunications companies to the importance of OL, whether for the individual or the organization, as learning helps the individual to develop his skills and abilities. For the organization, learning is an effective tool for dealing with continuous change in the environment, achieving the competitive advantage of the organization, and taking advantage of available and future opportunities.

\section{Future Research}

Although the current research sought to reveal the role of OS as an intermediate variable between OL and OE at Telecommunications sector in Egypt, the scope of this research and the methods used in it and its findings indicate that there are areas for future studies that are no less important in this regard. Among these research areas are: (1) the role of OL in achieving OE, (2) the relationship between OL and some other concepts such as strategic thinking, strategic management, (3) the reality of OL in the banking sector (4) the impact of OL on enhancing OS, (5) the role of strategic knowledge in achieving OL, (6) the impact of organizational resilience determinants on $\mathrm{OE}$, (7) the impact of the determinants of organizational agility on the competitiveness of companies, and; finally, (8) a comparative study between the determinants of organizational fitness in the business sector and the investment sector and its impact on $\mathrm{OE}$. 


\section{References}

Aga, D. A., Noorderhaven, N., \& Vallejo, B. (2016). Transformational leadership and project success: The mediating role of team-building. International Journal of Project Management, 34(5), 806-818. https://doi.org/10.1016/j.ijproman.2016.02.012

Ahmed, A., Elhag, M. (2017). SMART KM model: The integrated knowledge management framework for organizational excellence. World Journal of Science, Technology and Sustainable Development, 14(2/3), 172-193. https://doi.org/10.1108/WJSTSD-01-2017-0001

Al Hila, A. A., \& Al Shobaki, M. J. (2017). The Role of Servant Leadership in Achieving Excellence Performance in Technical Colleges-Provinces of Gaza Strip. International Journal of Management Research and Business Strategy, 6(1), 69-91.

Al-Dhaafri, H., Al-Swidi, A., \& Al-Ansi, A. (2016). Organizational Excellence as the Driver for Organizational Performance: A Study on Dubai Police. International Journal of Business and Management, 11(2), 47. https://doi.org/10.5539/ijbm.v11n2p47

Al-Dhaafri, H., Al-Swidi, A., \& Yusoff, R. (2016). The Mediating Role of TQM and Organizational Excellence, and the Moderating Effect of Entrepreneurial Organizational Culture on the Relationship between ERP and Organizational Performance. The TQM Journal, 28(6), 991-1011. https://doi.org/10.1108/TQM-04-2014-0040

Antony, J. P., \& Bhattacharyya, S. (2010) Measuring organizational performance and organizational excellence of SMEs - Part 2: an empirical study on SMEs in India. Measuring Business Excellence, 3(14), 42-52. https://doi.org/10.1108/13683041011074209

Berssaneti, F. T., \& Carvalho, M. M. (2015). Identification of variables that Impact Project Success in Brazilian Companies. International Journal of Project Management, 33(3), 638-649. https://doi.org/10.1016/j.ijproman.2014.07.002

Beyene, K. T., Shi, C. S., \& Wu, W. W. (2016). The Impact of Innovation Strategy on Organizational Learning and Innovation Performance: Do Firm Size and Ownership Type Make a Difference? South African Journal of Industrial Engineering, 27(1), 125-136. https://doi.org/10.7166/27-1-1308

Breyfogle, F. (2008). Integrated Enterprise Excellence, The Basics: Golfing Buddies Go Beyond Lean Six Sigma and the Balanced Scorecard. Pub Bridgeway Books and Citius Publishing, Inc, Austin USA, P.3.

Daniel S., \& John, R. B. (2004). High Performing Colleges: The Malcolm Baldridge National Quality Award as a Framework for Improving Higher Education, Theory and Concepts, Vol. I, Prescott Publishing Co., Maryville, 2004, P.24.

Dell, D., \& Kramer, R. (2003). Forging Strategic Business Alignment. The conference board.

Donsophon, K., Jhundra-indra, P., \& Raksong, S. (2016). Managerial Professionalism Strategy and Firm Success: Empirical Investigation of Hotel Businesses in Thailand. AU-GSB e-JOURNAL, 8(2), 141.

Döös, M., Johansson, P., \& wilhelmson, L. (2015). Organizational Learning as an Analogy to Individual Learning? A Case of Augmented Interaction Intensity, 8(1), 55-73.

Edmondson, A. C. (2002). The local and variegated nature of learning in organizations: A group-level perspective. Organization Science, 13(2), 128-146. https://doi.org/10.1287/orsc.13.2.128.530

Englbrt, D. (2003). Organizational Effectiveness. Book Internet.

Fleck, D., (2009). Archetypes of organizational Success and Failure. Brazilian Administration Review, Curitiba, 6(2), 78-100. https://doi.org/10.1590/S1807-76922009000200002

Fotis, K. V., \& Gotzamani, K. (2005). Best practices of selected Greek organizations on their road to business excellence: The contribution of the new ISO 9000:2000 series of standards. The TQM Magazine, 17(3), 259-266. https://doi.org/10.1108/09544780510594225

Fraj, E., Matute, J., \& Melero, I. (2015). Environmental strategies and organizational competitiveness in the hotel industry: The role of learning and innovation as determinants of environmental success. Tourism Management, 46, 30-42. https://doi.org/10.1016/j.tourman.2014.05.009

Gloet, M., \& Samson, D. (2017). Linking Knowledge Management, Business Excellence and Innovation Performance. In Proceedings of the $50^{\text {th }}$ Hawaii International Conference on System Sciences. https://doi.org/10.24251/HICSS.2017.557 
Golmoradi, R., \& Ardabili, F. S. (2016). The Effects of Social Capital and Leadership Styles on Organizational $\begin{array}{llll}\text { Learning. } \quad P r o c e d i a-S o c i a l & \text { and }\end{array}$ https://doi.org/10.1016/j.sbspro.2016.09.047

Grote, D. (2002). The Performance Appraisal Question and Answer Book Survival Guide for Managers. United States of America.

Hasson, H., Schwarz, U., Holmstrom, S., Karanika-Murray, M., \& Tafvelin, S. (2016). Improving Organizational Learning through Leadership Training. Journal of Workplace Learning, 28(3), 115-129. https://doi.org/10.1108/JWL-06-2015-0049

HesOLbein, F., \& Johnston, R. (2002). On Mission and Leadership: A Leader to Leader Guide. U.S.A.

Jones, G. R. (2000). Organizational Theory (3rd ed.). Prentice Hall, Englewood Cliffs, New Jersey.

Kandula, S. (2002). Strategic Human Resource Development. Meenakshi Printers, Delhi

Kenny, G. (2001). Strategic Factor: Developing and Measure Winning Strategy (1st ed.). National Library of Australia: President Press.

Kivipõld, K., \& Hoffman, C. (2016). Organizational learning in context of part-time employment: A case study of an Estonian media company. International Journal of Organizational Analysis, 24(4), 650-672. https://doi.org/10.1108/IJOA-06-2014-0779

Liao, S., Chen, C., Hu, D., Chung, Y., \& Liu, L. (2017). Assessing the Influence of leadership style, Organizational Learning and Organizational Innovation. Leadership \& Organization Development Journal, 38(5), 590-609. https://doi.org/10.1108/LODJ-11-2015-0261

Lilien, G., \& Gerwal, R. (2012). Hand book of business to Business Marketing. Edward Elgar Publishing, USA. https://doi.org/10.4337/9781781002445

Lin, H. F. (2008). Empirically Testing Innovation Characteristics and Organizational Learning Capabilities in E-business Implementation Success. Internet Research, 18(1), 60-78. https://doi.org/10.1108/10662240810849595

Louis, K., \& Murphy, J. (2017). Trust, Caring and Organizational Learning: the Leader's Role. Journal of Educational Administration, 55(1), 103-126. https://doi.org/10.1108/JEA-07-2016-0077

Lukito, H., Salleh, M. F. M., \& Husin, N. A. (2016). Organizational Learning as Moderating Variable between Human Resource Information System and Public Universities' Performance. Chinese Business Review, 15(11), 524-537.

Macmillan, H., \& Tampoe, A. (2000). Strategic Management. Oxford, UK.

Mahmood, S., Qadeer, F., \& Ahmed, A. (2015). The Role of Organizational Learning in Understanding Relationship between Total Quality Management and Organizational Performance. Pakistan Journal of Commerce and Social Sciences, (1), 282-302.

Maiga, A. (2015). Organizational Learning and Firm Profitability: The Role of Competitive Advantage. In Donna Bobek Schmitt (Ed.), Advances in Accounting Behavioral Research (Advances in Accounting Behavioral Research, Volume 18, pp. 179-211). Emerald Group Publishing Limited. https://doi.org/10.1108/S1475-148820150000018006

Mann, R., Mohammad, M., \& Agustin, M. T A., (2012). Understanding Business Excellence: An awareness guidebook for SMEs, Asian Productivity Organization.

Metaxas, I. N., Chatzoglou, P. D., \& Koulouriotis, D. E. (2017). Proposing a New Modus Operandi for Sustainable Business Excellence: the Case of Greek Hospitality Industry. Total Quality Management \& Business Excellence, 1-26. https://doi.org/10.1080/14783363.2017.1315934

Mohan, P. P., \& Sang, O. C. (2015). Exploring the Relationships between the Learning Organization and Organizational Performance. Management Research Review, 38(2), 126-148. https://doi.org/10.1108/MRR-02-2013-0033

Musawir, A., Serra, C. E. M., Zwikael, O., \& Ali, I. (2017). Project Governance, Benefit Management, and Project Success: Towards a Framework for Supporting Organizational Strategy Implementation. International Journal of Project Management. https://doi.org/10.1016/j.ijproman.2017.07.007 
Mutahar, A. Y., RaOLi, A. M., \& Al-Ghazali, B. M. (2015). Relationship of Transformational Leadership, Organizational Learning and Organizational Performance. International Journal of Economics and Financial Issues, 5(1S).

Nazem, F., \& Motalebi, A. (2011). The Structural Model for Intellectual Capital Based on Organizational Learning in Martyr Beheshti University. Quarterly Journal Approaches in Educational Administration, 2(5), 29-50.

Oh, S., \& Kuchinke, K., (2017). Exploring the Role of Organizational Learning Activities in the Quality Management Context. Leadership \& Organization Development Journal, 38(3), 380-397. https://doi.org/10.1108/LODJ-11-2015-0259

Pinar, M., \& Girard, T. (2008). Investigating the Impact of Organizational Excellence and Leadership on Business Performance: An Exploratory Study of Turkish firms. The SAM Advanced Management Journal, 73(1), $29-45$.

Porter, A., \& Steven, J. (2004). Assessing Business Excellence, Butter worth-Heinemann (2nd ed.).

Qawasmeh, F. M., Darqal N., \& Qawasmeh, I. F. (2013). The Role of Organization Culture in Achieving Organizational Excellence: Jadara University as a Case Study. International Journal of Economics and Management Science, 7(2), 5-19.

Ramakrishnan, R. (2004). Business Excellence of Industrial Groups in Oman. Measuring Business Excellence, 8(4), 34-44, https://doi.org/10.1108/13683040410569398

Rao, M. (2016). Collaborate to Build Effective Teams to Achieve Organizational Excellence and Effectiveness. Industrial and Commercial Training, 48(1), 24-28. https://doi.org/10.1108/ICT-01-2015-0010

Rao, M. S. (2015). Embrace Change Effectively to Achieve Organizational Excellence and Effectiveness. Industrial and Commercial Training, 47(3), 145-150. https://doi.org/10.1108/ICT-10-2014-0065

Saadat, V., \& Saadat, Z. (2016). Organizational Learning as a Key Role of Organizational Success. Procedia-Social and Behavioral Sciences, 230, 219-225. https://doi.org/10.1016/j.sbspro.2016.09.028

Saleem, M. A. (2017). The Impact of Socio-Economic Factors on Small Business Success. Geografia-Malaysian Journal of Society and Space, 8(1).

Saleh, A., \& Watson, R. (2017). Business Excellence in a Volatile, Uncertain, Complex and Ambiguous Environment (BEVUCA). The TQM Journal. https://doi.org/10.1108/TQM-12-2016-0109

Salleh, K. (2014). Learning Organization and Knowledge Management: Transfer Process of Tacit Knowledge in Public University for Academic Excellence. 11th International Conference on Intellectual Capital, Knowledge Management and Organizational Learning ICICKM.

Sharifi, A., \& EOLamieh, F. (2008). Examine the Relationship between Organizational Learning and Utilization of Information and Communication Technologies in IsLamic Azad University, Garmsar branch. Journal of Rahyafti No Dar Modiriat Amozeshi. First year. No 2.

Simon, A., Kumar, V., Schoeman, P., Moffat, P., \& Power, D. (2011). Strategic Capabilities and their Relationship to Organizational Success and its Measures: Some Pointers from five Australian Studies. Management Decision, 49(8), 305-1326. https://doi.org/10.1108/00251741111163133

Stratigos, A. (2001). Knowledge Management meets Future Information Users. Online col. 25(1), 65.

Terouhid, S., \& Ries, R., (2016). People Capability: A Strategic Capability for Enhancing Organizational Excellence of Construction Firms. Journal of Modeling in Management, 11(3), 811-841. https://doi.org/10.1108/JM2-04-2014-0028

Van Grinsven, M., \& Visser, M. (2011). Empowerment, Knowledge Conversion and Dimensions of Organizational Learning. The Learning Organization, 18(5), 378-391. https://doi.org/10.1108/09696471111151729

Wahyuningsih, A., Astuti, E., \& Al Musadieq, M. (2013). The Effect of Organizational Learning on Knowledge Management, Capability and Performance of Organization: Case Study in University of Brawijaya, Malang, Journal of Basic and Applied Scientific Research, University of Brawijaya. Malang of Indonesia, 3(5), 159-169.

Whitney, D. (2010). Appreciative Inquiry: Creating Spiritual Resonance in the Workplace. Journal of Management, Spirituality and Religion, 1-21. https://doi.org/10.1080/14766080903497656

Williams, A. (2001). A Belief- Focused Process Model of Organizational Learning. Journal of Management Studies, 38(1), PP.67-85. https://doi.org/10.1111/1467-6486.00228 
Yan, M., Yu, Y., \& Dong, X. (2016). Contributive Roles of Multilevel Organizational Learning for the Evolution of Organizational Ambidexterity. Information Technology \& People, 29(3), 647-667. https://doi.org/10.1108/ITP-04-2015-0079

\section{Copyrights}

Copyright for this article is retained by the author(s), with first publication rights granted to the journal.

This is an open-access article distributed under the terms and conditions of the Creative Commons Attribution license (http://creativecommons.org/licenses/by/4.0/). 